\title{
Moralization as protection against exploitation: do individuals without allies moralize more?
}

\author{
Michael Bang Petersen \\ Aarhus University, \\ Department of Political Science \& Government \\ Denmark
}

Running head:

Moralization as protection against exploitation

Correspondance to:

Michael Bang Petersen

Aarhus University

Department of Political Science \& Government,

Bartholins Allé 7

8000 Aarhus C, Denmark

Email: michael@ps.au.dk

Word count: 8,421

Accepted for publication in Evolution and Human Behavior 
Over the course of human evolutionary history, individuals have required protection from other individuals who sought to exploit them. Moralization-broadcasting relevant behaviors as immoral - is proposed as a strategy whereby individuals attempt to engage third parties in the protection against exploitation. Whereas previous accounts of strategic morality have focused on the effect of individual differences in mating strategies, we here argue for the importance of another factor: differences in the availability of alternative sources of protection. Given the potential costs of moralization, it is predicted that it is primarily used among individuals lacking protection in the form of social allies. Consistent with this, a large cross-national set of surveys is used to reveal how individuals without friends moralize more. In contrast, however, support from other social sources such as family or religious individuals increases moralization.

Humans evolved in a social world in which others were predisposed to exploit them if doing so was deemed self-beneficial. Consequently, the protection of one's resources such as food, tools, mates and status against encroachment from others has constituted important adaptive problems in the course of human evolutionary history (Petersen et al. 2012). Recent research has documented how humans have evolved an array of strategies designed to enforce such protection. Inspired by models of animal resource contests (Maynard Smith \& Parker 1976), it has been argued that individuals enhance their relative fighting ability to protect and negotiate for resources against other individuals by relying on their physical strength and/or coalitional allies (Sell et al. 2009; Tooby et al. 2006). In line with this, studies have shown that physically strong males feel more entitled to resources (Sell et al. 2009), are less willing to share resources (Price et al. 2010), and possess higher social status (Von Rueden et al. 2008). Similarly, people with large levels of social support have higher social status (Von Rueden et al. 2008) and are less likely to be exploited (Figuerado et al. 2001).

Individual formidability and allies are important sources of protection because they increase an individual's ability to impose costs, thereby deterring would-be exploiters. However, given the complexities of human social environments and the exceptional skills of humans for navigating them, other protective strategies are available. This article focuses on one such strategy: 
moralization. By tagging exploitive behavior as immoral, moralization enables individuals to activate moral outrage in third parties and engage the collective in the protection of their resources against exploiters. Given specific non-trivial costs of moralization as a protective strategy, this strategy is predicted to be more likely to be adopted by individuals with limited ability to enforce their private interests in alternative ways.

\section{Moralization as protection}

Over the course of human history, punitive strategies have evolved as a key deterrence device. Punishment involves the imposition of costs and, through hard-to-fake signals of punitive intent, individuals can use punishment to deter would-be exploiters by altering the cost-benefit calculus associated with exploitive actions. Because punishment works through cost imposition, factors that are positively correlated with the ability to impose costs, such as individual formidability (Sell et al. 2009) and the number of close coalitional allies (Tooby et al. 2006), increase an individuals' ability to promote their interests and protect their resources.

Throughout the animal kingdom, organisms engage in punishment and aggression to deter against exploitive organisms that directly target their own interests or the interests of their kin or close social allies (Clutton-Brock \& Parker 1995). Such punishment is commonly labeled second-party punishment and distinguished from the zoologically rarer phenomenon of third-party punishment (DeScioli \& Kurzban 2009; Fehr \& Fischbacher 2004; Lieberman \& Linke 2007). Third-party punishment - where organisms punish exploitive acts that do not directly harm them -is often observed within the human species but rarely outside. For humans, the existence of cognitive systems implementing third-party punishment opens up an alternative route to protection: to the extent the collective in the form of otherwise disinterested third parties can be engaged in the 
protection of a resource, this resource can be kept safe from exploiters even for individuals without high levels of individual formidability or close social allies.

Natural selection should prepare us to manipulate any enduring cognitive system in the minds of others for our own benefit (see, e.g., Buss 1988; Buss \& Dedden 1990). The cognitive systems underlying third-party punishment are potential targets for such attempts at manipulation. In particular, individuals without alternative sources of protection could benefit from manipulating the propensity of others to engage in third-party punishment if this punishment can be directed toward people who challenge the interests of the individual.

In humans, engaging in third-party punitive behavior appears to be linked to a particular cognitive and motivational state, commonly labeled moral outrage. This psychological state involves a cascade of cognitive and affective processes supporting the execution of punishment (Tetlock et al. 2000). When outrage becomes activated, the traits of norm violators are judged more harshly, emotions of anger and contempt are triggered, and support for norm enforcement and meta-norm enforcement is facilitated. In other words, outrage facilitates the punishment of norm violators as well as those who do not contribute to this punishment. Hence, in principle, individuals can direct the third-party punishment of others by tapping into the outrage system and increasing the moral outrage felt against certain classes of acts (see also DeScioli \& Kurzban 2011; Jensen \& Petersen 2011; Kurzban et al. 2010; Tooby \& Cosmides 2010). ${ }^{1}$ We will term such attempts at strategic manipulation moralization.

\footnotetext{
${ }^{1}$ This effect is related to at least two features that bystanders can gauge from a signal of moral outrage. First, outrage reveals that the sender believes that the target act indirectly hurts his or her interests. Given the complexities of human social interaction, it is individually difficult to constantly monitor downstream welfare effects of each and every action that others engage in and, hence, any information about other people's assessments in this regard should be valuable. The role of these kinds of social learning effects is evident in, for example, the literature on bystander effects, where bystanders take cues from others about whether to intervene (see in particular Dedrick 1978). Second, outrage provides a credible signal that the sender is willing to engage in third-party punishment (cf. Frank 1988), thereby lowering the costs of others to join to effectively deter the relevant class of acts. In this regard, it is also of key importance to notice that if coordination should be orchestrated de novo each and every time a relevant exploitive act was undertaken, costs would be massive (Tooby et al. 2006). One way of countering such costs comes from humans' exceptional cognitive skills for building and committing to social norms in the sense of shared expectations (O'Gorman et al. 2008). To
} 


\subsection{Trade-offs in moralization: individual differences in strategy and formidability}

To flesh out the observable implications of this view, we need to carefully consider (1) moralization as an adaptive problem entailing fitness costs and benefits and (2) how these costs and benefits should be reflected in the evolved design of a cognitive system for outrage manipulation.

What individual benefits would successful moralization entail? To the extent an individual can successfully tag actions that are privately problematic as immoral, they would effectively be transformed from the individual's problem into the collective's problem. By implication, the individual can draw on processes of third-party punishment to protect the good in question. For example, to the extent adultery is morally condemned, the third-party punishment following acts of adultery adds an extra layer of deterrence and provides added insurance for those with fears regarding the fidelity of their partner. Hence, while having a faithful partner is a private good—it specifically benefits that very individual whose partner is faithful—-the successful moralization of fidelity turns the problem of unfaithful partners into the problem of the collective and, hence, the collective becomes engaged in protecting the private good of faithfulness.

At the same time, it is important to note that moralization comes with costs. From the perspective of the self, the problem is that moral rules constrain the behavior of everybodyincluding the self. By moralizing a certain behavior, the self becomes excluded from engaging in the very behavior, in the sense that by doing so the self would find him or herself the object of the moral outrage he or she initially helped orchestrate against others. In this way, moralization will deprive the self of a number of potentially fitness-enhancing strategies. Again, adultery can serve as

counter the coordination costs in relation to the coordination of third-party punishment, it is, in other words, plausible that group members recognize and react on the basis of a momentarily stable "portfolio" (i.e., mental catalogue) of goods that a sufficient part of the collective recognizes as so valuable that it is prudent to deter acts that target them through coordinated punishment. On the one hand, the existence of such a portfolio provides a public good in that everybody enjoys the benefits of deterrence. In this regard, it is also important to recognize that the effectiveness of punishment and the coordination problems related to moving new acts into the portfolio imply that whenever coordination is achieved and the collective locks in to deter a particular class of exploitive acts, it could pay for individuals to join in and support coordinated punishment, even if they would themselves have prioritized deterring another class of acts (DeScioli \& Kurzban 2012). 
an example. While infidelity of one's partner toward the self entails a fitness cost to the self, the adultery of the self can potentially entail fitness benefits (see Buss 1994). Yet moralizing fidelity not only binds the partner but also the self. One could even argue that moralization binds the self stronger than it binds others. Hence, accusing someone of being a hypocrite is basically tantamount to announcing the detection of strategic moralization and, as suggested by anecdotal evidence on an issue such as the sexual escapades of conservative politicians and priests, third-party condemnation is only magnified when the accusation of immorality is topped off with accusations of hypocrisy. Further along these lines, laboratory studies show that high-status individuals (i.e., people expected to perform as role models) are often punished for moral violations harsher than low-status individuals (e.g., Feather \& Atchison 1998). In fact, one could view this acute attention to and animosity toward moral hypocrisy as independent support for a recurrent role of strategic moralization in social interaction.

Overall, this implies that while successful individual-level moralization can engage the collective in the protection of valued resources, this entails the costs of foregoing opportunities for pursuing self-interests or engaging in hypocrisy and paying the extra costs upon detection. To the extent that decisions about whether to moralize or not have constituted a recurrent adaptive problem throughout human evolutionary history, we should expect our minds to contain cognitive systems designed to weight these costs and benefits in the face of the specific circumstances facing us. In this regard, one obviously important factor relates to stable individual differences in social strategy (DeScioli \& Kurzban 2012; Kurzban et al. 2010; Weeden et al. 2008). For example, there are relatively stable individual differences in mating strategies, where some people follow a longterm mating strategy (securing reproduction by investing in long-term relationships such as marriage) and others a short-term mating strategy (securing reproduction by seeking short-term sexual encounters) (e.g., Belsky et al. 1991; see also Buss \& Schmitt 1993). Importantly, the 
cost-benefit calculus about whether to morally condemn sexual promiscuity is very different for the people following these respective strategies. An individual following a long-term mating strategy stands to pay far fewer costs by condemning promiscuity, because this individual is less likely to engage in such behavior than a person following a short-term mating strategy. Indeed, previous research consistently finds that those following long-term mating strategies are much more likely to moralize behavior related to promiscuity compared to people following short-term mating strategies (Kurzban et al. 2010; Weeden et al. 2008). Individual differences in mating strategies constitute just one example of how individual strategy differences within different domains could change the cost-benefit ratios of the moralization of behavior within the domain. Other strategy differences could relate to, for example, cooperation behavior (Fischbacher et al. 2001) and conflict behavior. Most previous research has focused on such differences in the strategy on moralization. Yet while individuals following, for example, a cheating strategy would stand to gain from being allowed to cheat on others, it is important to note that these individuals still face the problem of protecting themselves against the cheating behavior of others. This suggests that another important class of individual differences determining how to trade-off the costs and benefits associated with moralization relates to the general ability of individuals to protect their resources against exploitation from others. As argued above, individual differences in the ability to impose costs, i.e., formidability, are a key regulator of differences in protective capacity. Whereas individual differences in mating or cooperative strategies should influence the tendencies to moralize behavior falling within the relevant domains, individual differences in formidability should influence tendencies to moralize across domains. Hence, given the costs associated with moralization, moralization within any domain is most adaptive among those who are not able to protect their own resources in alternative ways. Individuals who (1) follow potentially exploitive strategies and (2) are capable of protecting themselves from exploitation will often be better off 
without engaging in moralization, as this opens up for the possibility of exploiting others without incurring the costs of moral outrage. To the extent moralization involves attempts at strategic manipulation, we should therefore expect an individual's general propensity to moralize to correlate negatively with the factors determining individuals' abilities to protect themselves in the absence of moralization.

This article focuses on one particular ancestrally important component of individual formidability: the number of social allies an individual can draw upon in conflict situations (Chapais 1995; DeScioli \& Kurzban 2009; DeScioli et al. 2011). Given the small-scale nature of ancestral social groups, even small numerical differences in allies would have important consequences for an individual's ability to impose costs on others (Sell et al. 2009; Tooby et al. 2006). Given this, we predict the existence of an inverse relationship between available social allies and moralization. Individuals with fewer social allies are predicted to moralize more because they are more vulnerable to exploitation. To be clear, the argument is not that people with allies accept adultery, violence, and theft when it is directed against themselves. But people with many allies have other means of protecting their resources, which leaves open the possibility of engaging in exploitive behavior themselves.

\section{Empirical test I: moralization and types of allies}

On the basis of the above discussion, we predict that individuals with fewer social allies moralize more. Importantly, however, this is not the first theory to address the relationship between morality and social support. A number of previous studies have suggested that mating strategies constitute a basic motivational force that simultaneously influences the social networks one builds and the moralization behavior one engages in (Weeden et al. 2008). This link between strategies and social support could interfere with the proposed negative effect of having allies on moralization. To 
disentangle these cross-cutting effects, it becomes necessary to dissect the concept of social allies more and, in particular, discuss the different sources of social allies available to individuals.

Ancestrally as today, there are at least three sources from which an individual can receive social support: friends, family (e.g., spouse, parents, siblings), and individuals from the larger community in which the individual is situated in. As social support from each of these sources should increase the leverage of an individual in conflict situations, the immediate prediction is that moralization would decrease with increasing support from these sources. At the same time, previous research might suggest that the relationship between moralization and social support is unique for friendships and that support family and community sources work differently. We now discuss each source of support in turn.

Previous research suggests that the links to a sense of formidability are particularly strong for a specific source of support: friendships. DeScioli \& Kurzban (2009) suggest that the key reason we evolved cognitive systems for forging friendships was to amplify one's individual bargaining power in conflict situations (see also Tooby et al. 2006). In line with this proposed role of friends in enforcing one's interests, studies among both Western children and Amazonian foragers demonstrate that friendships represent a highly important means of achieving social status in groups (Berndt 2002; von Rueden et al. 2008). Furthermore, research on antisocial behavior in adolescents consistently shows that individuals who spend more time with friends are more likely to engage in such behavior (Haynie \& Osgood 2005; Riley 1987). Importantly, this effect does not (just) reflect peer socialization, as the effect remains whether or not these friends are antisocial themselves (Haynie \& Osgood 2005). Rather, what seems to be decisive in promoting predatory behavior is to have friends who are willing to stand up for the self (Zhang \& Zhang 2004). These observations suggest that having friends not only helps protect the resources of the self but also 
makes it more attractive to exploit others. Both dynamics make moralization a less attractive strategy for individuals with friends.

The observations from previous research focusing on family support are more mixed. In line with the proposed role of allies in enforcing one's interests, cross-cultural studies show that females living in proximity of dense kin relations are much less likely to fall victim to spousal abuse than females living distantly from their kin. Conversely, males inclined to use abuse as a mate retention tactic are much more prone to do so if living in proximity to kin (Figueredo et al. 2001). At the same time, investments in family relationships are an obvious indicator of a long-term mating strategy (Buss \& Schmitt 1993), which would render it advantageous to moralize behavior that disrupts relationships and, hence, potentially offsets any opposing effects of increased formidability.

This latter argument has been developed explicitly in relation to a specific kind of community: religious communities. Religious individuals tend to hold more conservative values (Layman 1997) and, in particular, religious attendance is strongly related to moralization in the sexual domain (Weeden et al. 2008). In fact, Weeden et al. (2008) suggest that long-term mating strategies are a key force driving people into religious communities and, by implication, those who receive support from religious others moralize some issues (especially family-related issues) even more than those without such support. This opposing effect of social support from religious individuals is joined by another: a number of theories argue that for certain sources of support—and, in particular, support from religious communities - adherence to moral rules work as a costly signal of one's commitment to the community (e.g., Sosis \& Alcorta 2003). By implication, support becomes contingent on the self's observation of moral rules, which again would interfere with the theory proposed here. In general, these lines of research suggest that support from such communities does not reduce moralization. 
In sum, these observations suggest that the predicted causal effects of social support are specifically associated with support from friends. Support from other sources (e.g., family and communities organized around moral principles, such as religious communities) could serve more as a reflection of differences in mating strategies rather than as input to individual formidability. To investigate these potential opposing effects of social support, we differentiate between support from these three sources and investigate the effects of each.

\subsection{Materials and methods}

All of the empirical tests are based on samples drawn from an existing set of opinion surveys collected across a range of countries: the European Values Study (EVS). Since 1981 and 2008, four waves of this survey have been collected. In 1999, a wave of the EVS was conducted containing a range of questions relating to moralization as well as number of social allies. By focusing on this particular survey wave, we are able to perform tests that maximize measurement validity and, hence, provide the strictest possible test of the theoretical account. In 32 countries, respondents have been asked an extensive battery of moralization questions as well social support questions. ${ }^{2}$ To maximize the consistency and validity of our measurement, we focus exclusively on respondents from these 32 countries, which in total constitute a sample of 31,786 individuals. These individuals form the core sample for our empirical tests. ${ }^{3}$

Testing the main prediction requires the operationalization of two basic constructs: the moralization of exploitive behavior and support from the three sources of social allies. To measure moralization, we utilize a range of questions where respondents were asked to indicate on a scale from 1-10 whether specific kinds of behavior were "Never justifiable" (1), "Always justifiable"

\footnotetext{
${ }^{2}$ Austria, Belgium, Bulgaria, Belarus, Croatia, Czech Republic, Denmark, Estonia, Finland, France, Germany, Great Britain, Greece, Hungary, Iceland, Ireland, Italy, Latvia, Lithuania, Luxembourg, Malta, the Netherlands, Northern Ireland, Poland, Portugal, Romania, Russian Federation, Slovakia, Slovenia, Spain, Sweden and Ukraine.

${ }^{3}$ The exact number of participants used in each test varies, however, as some of the other variables were included in a fewer country surveys. Hence, Ns are consistently reported for each performed test.
} 
(10), or somewhere in between. One important aspect of a moral rule is that it is not possible to justify violations (Turiel 1983) and, hence, this form of questioning taps into a significant aspect of the extent to which the respondent moralizes the given behavior. Behaviors that were asked about include behaviors in the sexual domain (e.g., adultery), behaviors relating to violations of nonsexual private goods (e.g., lying), and behaviors relating to public goods (e.g., cheating on one's taxes). In the 32 countries used, respondents have been asked a large battery of 18 questions. The full list of behaviors asked about is: someone accepting a bribe, cheating on taxes, driving under the influence of alcohol, lying, littering, speeding, joyriding, fraudulently claiming government benefits, paying cash to avoid sales taxes, adultery, smoking in public building, taking soft drugs, divorce, abortion, homosexuality, euthanasia, suicide, and having casual sex. Across these countries, the reliability of a scale combining answers to moralization questions is highly satisfactory $(\alpha=0.86)$. Answers to all of the available moralization questions were added together to form a scale of moralization. A high value on the scale corresponds to high levels of moralization. As described in the theory section, we seek to build three distinct measures of social support. While the main theoretical hypothesis is that social support decreases moralization, past research suggests that two particular kinds of social support-support from religious groups and support from family — could work differently. Hence, our primary variable of interest is a measure of whether or not the respondent has support from friends to draw upon in conflict situations. Here, we use a question relating to how often the respondent spends time with friends. The respondent was asked to indicate whether time was spent weekly, once or twice a month, only a few times each year, or never at all. A high value on this measure corresponds to high levels of support from secular, peer allies. 
To measure social support from religious individuals, there was a comparable measure available. Hence, respondents were also asked how often they spend time with people at their church, mosque, or synagogue. This constitutes our measure of support from religious individuals.

To measure support from family, we need to rely on a less comparable measure, as the EVS 1999 did not ask how often they spend time with family. Instead, we focus on the closest available proxies in the data set: whether or not respondents live together with their parents and whether or not they are married. We combine these two sources of family support in a single formative index, higher values indicating greater family support.

These variables constitute our main variables of theoretical interest. We include a range of important individual-level control variables: sex, age, number of children, level of education (high, medium, or low, relative to countrymen), and level of income (high, medium, or low, relative to countrymen). Furthermore, we control for the subjective importance attributed to friends, family, and religion. By comparing the effects of actually having support from these sources with merely thinking of these sources as important, we are able to test whether the effect in question is driven by individual differences in preferences (e.g., extraversion should be related to both having and wanting friends) or the theoretically expected trade-offs that are exclusive to actually having social support.

\subsection{Results}

In Table 1, moralization has been regressed on the social support variables controlled for age. All of the reported coefficients are standardized regression coefficients. As seen, all social support variables have significant effects on the proneness of individuals to moralize exploitive behavior. Importantly, however, the effects run in different directions. In line with the theoretical argument, Table 1 reveals that having peer social support decreases people's tendency to moralize. People 
who have friends to draw upon in situations involving conflict are slightly less likely to protect resources through moralization. In contrast, social support from family or religious others increases people's tendency to moralize. Hence, in line with previous research (e.g., Weeden et al. 2008), the negative effects of social support on moralization are limited to having secular friends.

\section{- TABLE 1 ABOUT HERE -}

In terms of effect sizes, the effects are relatively small compared to the most powerful determinants: age (older people moralize more) and religiosity (religious individuals moralize more). At the same time, the size of the effects should be judged relative to the fact that they are controlled for the range of other variables - both demographic and attitudinal. Most importantly, the effects of all social support measures have been controlled for the subjective importance attributed to the particular source. Hence, the effects of our support measures are not contaminated by preferences for the source but show the effect of actually enjoying support from the source.

\section{Empirical test II: moralization across domains}

The first test provided evidence that social support influences moralization in diverse ways. In line with previous research, support drawn from family or religious segments makes people more likely to moralize (e.g., Weeden et al. 2008). In contrast, having allies in the form of friends makes people less likely to follow a moralization strategy. This is consistent with the theoretical claim that there are trade-offs involved in moralization and, if other avenues of resource protection are available, the moralization strategy is not utilized to the same degree.

The effects of religious and family support are consistent with claims that individual differences in social strategies influence moralization behavior. For example, people following 
short-term mating strategies are less likely to condemn sexual behavior due to strategic considerations (Kurzban et al. 2010; Weeden et al. 2008). In contrast, the effect of friends is argued to reflect differences in formidability rather than differences in strategy. Having friends does not merely reflect a specific social strategy but also the ability to protect what an individual values given his or her strategy. These two effects are, however, difficult to disentangle. Hence, those pursuing a short-term mating strategy might be more willing to seek out opposite-sex friends as potential short-term mates (Lewis et al. in press) and moralize behaviors related to short-term mating less. If, however, the effect of having friends is exclusively related to mating strategies, we should find that the effects of social support from friends exclusively influence moralization within the mating domain. If, on the other hand, the effects of social support from friends reflect differences in formidability, its effects should generalize across moral domains.

\subsection{Materials and methods}

To test the extent to which the effect of having friends generalizes across different domains of moralization, we again use the same sample from EVS 1999 as defined above. The investigation requires us to fractionate the moralization scale used in the first set of tests into distinct domains and investigate the relationships between the resulting measures and different social support measures.

We apply factor analysis toward this end. All of the moralization items described above were subjected to an exploratory principle factor analysis from which only two factors emerged with Eigen values above the Kaiser criterion of 1.0. To facilitate interpretation, these factors were subjected to oblique rotation and the loadings are displayed in Table 2. As shown in the table, the first factor seems to relate to behavior that targets cooperative enterprises in diverse ways, including free-riding in the context of public goods, breaking laws, and exploiting the 
trustworthiness of others. The second factor is exclusively related to behaviors within the mating domain and, specifically, apparently behavior that harms long-term mating unions. The only item that does fit this pattern fully is related to adultery, which loads on the cooperation rather than mating dimension (perhaps due to the betrayal of trust involved). For each of these two factors, factor scores were saved.

- TABLE 2 ABOUT HERE -

We control for the same set of variables as above, and all of the reported coefficients are again standardized regression coefficients.

\subsection{Results}

In Table 3, the two moralization measures have been regressed on the social support variables and the control controlled for age and country.

\section{- TABLE 3 ABOUT HERE -}

The first model presents the findings for moralization within the domain of mating. These results replicate the findings from Table 1 almost exactly. Hence, within the domain of mating, there is a small and negative effect of allies in the form of friends such that more friends imply less moralization of behavior harmful to long-term mating relationships. Again, in line with previous research, the other support variables have effects in the opposite direction. The second model presents the findings for moralization within the cooperative domain. As can be seen, the effects of social support are generally weaker. In particular, and in line with claims about an intricate link 
between religiosity and mating behavior (Weeden et al. 2008), the effect of social support from religious others drops from being among the strongest predictors of moralization of mating to being much weaker. At the same time, it is important to note that all social support variables continue to be significant and their direction is unchanged from one domain to the other.

This provides some measure of support for the claim that their effects are not exclusively tied to differences in mating strategies. In the case of support from religious others and family, this could suggest that their effects are also related to signaling purposes (cf. the theory section). In the case of friends, the effect across domains supports the formidability-oriented account. At the same time, it should be noted that these analyses show that the effects for all social support are indeed strongest on moralization in the domain of mating. In the Online Supplemental Material, we have added additional analyses on another EVS wave 1981 containing question batteries about moralization but have other, less optimal measures of social support from friends

and family. These analyses suggest another pattern, where the effects of social support are strongest for moralization outside the domain of mating. This adds further evidence that the effects of social support are not exclusively related to differences in strategies.

\section{Empirical test III: support from friends and differences in social strategies}

The method used in the above of fractioning moralization into different domains did not provide clear-cut results as to whether the effect of having friends on moralization is a matter of different mating strategies. The effect was stronger for moralization in the mating domain in the main dataset, but the effect continued to be significant on behavior outside the mating domain. Furthermore, an alternative dataset yielded other results, with the effects of spending time together with friends being stronger outside the mating domain. In this final set of analyses, we therefore try 
to directly model individual differences in social strategies in the respective domains and analyze how friendships moderate the effects of these strategies.

Moralization is argued to be a protective strategy that individuals can pursue to protect themselves from mate poaching, theft, and other types of exploitive behavior. The cost of a protective moralization strategy is primarily that it makes it more difficult for individuals to pursue their own strategies to the extent that these strategies imply engaging in the condemned behavior. Hence, as argued in the theory section, individuals who (1) follow potentially exploitive strategies such as strategies of free-riding and mate poaching but (2) are capable of protecting themselves against free-riders and mate poachers by virtue of having allied friends will often be better off without engaging in moralization. In contrast, individuals following these strategies who are unable to protect themselves from the same strategies due to a lack of friends are predicted to engage in the moralization of these behaviors to protect themselves. In this final set of tests, we explore whether individual differences in strategies and friendships interact in this manner.

\subsection{Materials and Methods}

We continue with the variables from the previous sets of tests and only need to obtain direct measures of individual differences in social strategies within the two domains of mating and cooperation. Given the available measures in the EVS, we build a measure of investments in longterm mating relationships to gauge strategy differences in the mating domain. A summary scale was built from the degree of agreement with these four statements: "A long-term relationship is necessary to be happy," "Women want a home and children," "Fathers are well-suited for looking after children," and "A man has to have children to be fulfilled" $(\alpha=0.54)$. A high value on the scale reflects a high investment strategy. 
To establish a comparable measure in the domain of cooperation, we focus on investments in cooperative relationships and utilize a range of questions about whether the subject is prepared to help a diverse range of groups. Specifically, the subject was asked whether he or she was prepared to help immediate family, people in the neighborhood, the elderly, immigrants, and the sick and disabled. Answers were provided on 5-point scales from "absolutely yes" to "absolutely no." From the five items, a summary scale was created $(\alpha=0.82)$, with high values reflecting a high investment strategy.

We control for the same set of variables as above, and all of the reported coefficients are again standardized OLS regression coefficients.

\subsection{Results}

To examine the dual impact of strategies and friendships, we model two-way interaction terms between the strategy and social support from friends on the relevant moralization behavior. In Table 2, the first model shows the effect of the interaction between the level of investment in family and friendships on moralization in the mating domain. As can be seen, the interaction term is significant. This implies that people with the same investment strategy differ in their moralization behavior depending on the support they have from friends. A similar effect can be observed in the second model showing the interaction between levels of cooperative investments and friendship on moralization in the domain of cooperation. This interaction term is also significant.

\section{- FIGURE 1 ABOUT HERE -}

For ease of interpretation, the interaction effects are illustrated graphically in Figure 1. For each of the two domains, the graphs show the predicted levels of moralization measured on a scale from 0 
(low moralization) to 1 (high moralization) conditioned by individuals' investment strategies in the given domain as well as their level of support from friends. The black lines show moralization for individuals with low levels of friendship support, whereas the gray lines indicate moralization for those with high levels of support. As predicted, in both domains, the individuals following a high investment strategy in the respective domain moralize the kinds of behavior running counter to these strategies (e.g., divorce and casual sex in the mating domain and stealing and lying in the cooperation domain). They do so irrespective of whether or not they have social allies in the form of friends. However, this pattern changes substantially for the individuals following a low investment strategy, whereby support from friends plays a non-trivial role for moralization behavior. As predicted, while it seemingly goes against their immediate strategic self-interest, individuals without allied friends continue to condemn low investment behavior in others despite following a low investment strategy themselves. In contrast, individuals following a low investment strategy who are able to draw on allied friends to protect their own resources are significantly less prone to condemn the relevant behavior. This suggests that individuals without alternative sources of protection opt for a moralization strategy even if it runs counter to their interests from a social strategy perspective and, hence, supports the argument that moralization is, at least in part, engaged in for reasons for protection of resources against exploitation from others. While some individuals might want to pursue a free-riding strategy themselves, they seek, for example, to use moralization to protect themselves from free-riding by others if no alternative deterrents are available. This basic pattern is comparably similar across the two domains, although the main effect of the strategy is stronger in the domain of mating, and the interaction effect with friendships is stronger in the domain of cooperation.

Further analyses (available in the Online Supplemental Materials) show that this pattern of relationships is unique for friends as a source of social support - neither support from 
religious others or family interactions with investment strategy in the cooperation domain. Both, however, interact with investment strategy in the mating domain but in completely different ways than was the case with friendship. Hence, the analyses show that people following low investment strategies but who are provided with support from family and religious individuals moralize behavior in this domain to a significantly greater degree than people without such support. This suggests that moralizing behavior could also serve signaling purposes such that one seeks to sustain support from social sources by moralizing behavior that targets the resources that these sources cherish.

\section{Discussion and conclusion}

This article has argued that signals of moral outrage can be viewed as attempts at mobilizing third parties to punish behaviors directed against valued resources. In line with this, previous studies have demonstrated that individual differences in preferences - in particular, as reflected in mating strategies_-influence people's tendencies to moralize. People seemingly use moralization to constrain behavior that specifically targets their interests rather than to constrain antisocial behavior as such (Kurzban \& DeScioli 2012; Kurzban et al. 2010; Weeden et al., 2008). Individuals following long-term mating strategies are, for example, particularly likely to become outraged at behavior that harms long-term sexual relationships compared to those following short-term mating strategies. The present article has added to this literature by focusing on an additional factor influencing strategic moralization: individual differences in coalitional formidability.

Using data from a large number of individuals from 32 Eurasian countries, it has been shown (1) that individuals with fewer friends are more likely to moralize, (2) that this applies in both the domain of mating and (to a lesser extent) the domain of cooperation, and (3) that individuals without friends even tend to moralize behavior that goes against their immediate 
preferences such that those preferring to not invest in long-term mating relationships or in cooperative relationships still condemn such behavior in others. While these effects were relatively limited in terms of effect sizes, they were robust to control for a large range of potentially confounding variables.

The findings suggest that moralization is not merely an attempt at promoting one's immediate preferences within a specific domain but also serves a more general protective function. People without alternative sources of protection (e.g., allied friends) apparently use moralization to deter potential exploitation across domains. In this way, this study adds to the literature on strategic morality (Cronk 1994; DeSciolo \& Kurzban 2011; Kurzban et al. 2010; Tooby \& Cosmides 2010) by showing how strategic concerns not only influence the content of the self's preferred moral rules (e.g., that mating strategy influences the propensity to moralize actions leading to promiscuous sexual behavior, cf. Kurzban et al. 2010; Weeden et al. 2008) but also that strategic concerns influence the self's more general propensity to invoke moralization as a protection device.

At the same time, the analyses clearly indicated that not all types of social support had similar effects. Three types of support were compared: from friends, from family, and from religious others. Whereas social support from friends reduced moralization, support from family and religious others increases moralization. As discussed in the theory section, this most likely reflects the conclusion from previous studies that the differences in support from these latter sources reflect differences in mating strategies. In particular, involvement in religious communities has been shown to reflect a long-term mating strategy which increases the condemnation of promiscuity (Weeden et al. 2008). With regards to the observed effects of family support, it should be noted that this is possibly a reflection of the particular operationalization of family support. Hence, family support was operationalized as being married and living together with one's parents. To the extent 
other indicators had been used that focused more on peer support among kin-such as time spent with cousins and siblings - the effects could have been different (see Tooby \& Cosmides 2000).

In sum, the present findings suggest that an individual's tendency to moralize reflects the strategic concerns of that specific individual. While cognitive systems for morality could have evolved to facilitate altruistic behavior as a number of researchers have argued (e.g., Frank 1988; Haidt 2007; Wilson 2002), their existence would have generated independent selection pressures for manipulating them in the minds of others. If the findings of the present article are any indication, these selection pressures could have moved parts of human moral reasoning in more self-serving directions. Support for moral rules not only reflects group-oriented concerns but also attempts to manipulate the social environment in self-interested ways.

\section{References}

Belsky, J., Steinberg, L., \& Draper, P. (1991). Childhood experience, interpersonal development, and reproductive strategy: An evolutionary theory of socialization. Child Development, 62, $647-670$.

Berndt, T. J. (2002). Friendship quality and social development. Current Directions in Psychological Science, 11, 7-10.

Buss, D. M. (1988). The evolution of human intrasexual competition: Tactics of mate attraction. Journal of Personality and Social Psychology, 54, 616-628.

Buss, D.M. (1994). The evolution of desire: strategies of human mating. New York: Basic Books.

Buss, D. M., \& Dedden, L. (1990). Derogation of competitors. Journal of Social and Personal Relationships, 7, 395-422.

Buss, D. M., \& Schmitt, D. P. (1993). Sexual strategies theory: an evolutionary perspective on human mating. Psychological Review, 100, 204-232.

Chapais, B. (1995). Alliances as a means of competition in primates: evolutionary, developmental, and cognitive aspects. American Journal of Physical Anthropology, 38, 115-136.

Clutton-Brock, T. H., \& Parker, G. A. (1995). Punishment in animal societies. Nature, 373, 209-216.

Cronk, L. (1994). Evolutionary theories of morality and the manipulative use of signals. Zygon: Journal of Religion and Science, 29, 81-101. 
Dedrick, D. K. (1978). Deviance and sanctioning within small groups. Social Psychology, 41, 94-105.

DeScioli P., \& Kurzban R. (2009). The alliance hypothesis for human friendship. PLoS ONE, 4, e5802.

DeScioli P., \& Kurzban R. (2012). A solution to the mysteries of morality. Psychological Bulletin, published online July 2.

DeScioli, P., Kurzban, R., Koch, E. N., \& Liben-Nowell, D. (2011). Best Friends. Perspectives on Psychological Science, 6, 6-8.

Feather, N. T., \& Atchison, L. (1998). Reactions to an offence in relation to the status and perceived moral character of the offender. Australian Journal of Psychology, 50, 119-127.

Fehr, E., \& Fischbacher, U. (2004). Third-party punishment and social norms. Evolution and Human Behavior, 25, 63-87.

Figueredo, A. J., Corral-Verdugo, V., Frías-Armenta, M., Bachar, K. J., White, J., McNeill, P. L., Kirsner, B. R., \& Castell-Ruiz, I. P. (2001). Blood, solidarity, status, and honor: the sexual balance of power and spousal abuse in Sonora, Mexico. Evolution and Human Behavior, 22, 295-328.

Fischbacher, U., Gächter, S., \& Fehr, E. (2001). Are people conditionally cooperative? Evidence from a public goods experiment. Economic Letters, 71, 397-404.

Frank, R. H. (1988). Passions within reasons: the strategic role of the emotions. New York: W.W. Norton.

Haidt, J. (2007). The new synthesis in moral psychology. Science, 316, 998-1002.

Haynie, D. L., \& Osgood, D. W. (2005). Reconsidering peers and delinquency: how do peers matter?, Social Forces, 84, 1109-1130.

Jensen, N.H. \& Petersen, M.B. (2011). To defer or to stand-up? How offender formidability affects third party outrage. Evolutionary Psychology, 9, 118-136.

Kurzban, R., Dukes, A., \& Weeden, J. (2010). Sex, drugs, and moral goals: reproductive strategies and views about recreational drugs. Proceedings of the Royal Society-B. Published Online.

Layman, G. C. (1997). Religion and political behavior in the United States: the impact of beliefs, affiliations, and commitment from 1980 to 1994. The Public Opinion Quarterly, 61, 288-316.

Lewis, D. M. G., Al-Shawaf, L., Conroy-Beam, D., Asao, K., \& Buss, D. M. (in press). Friends with benefits II: mating activation in opposite-sex friendships as a function of sociosexual orientation and relationship status. Personality and Individual Differences.

Lieberman, D., \& Linke, L. (2007). The effect of social category on third party punishment. Evolutionary Psychology, 5, 289-305.

Maynard Smith, J. \& Parker, G. A. (1976). The logic of asymmetric contests. Animal Behavior, 24, 159-75.

O'Gorman, R., Wilson, D. S., \& Miller, R. R. (2008). An evolved cognitive bias for social norms. Evolution and Human Behavior, 29, 71-78. 
Petersen, M. B., Sell, A., Tooby, J., \& Cosmides, L. (2012). To punish or repair? Evolutionary psychology and lay intuitions about modern criminal justice. Evolution and Human Behavior, published online July 16.

Price, ME., Kang, J., Dunn, J. \& Hopkins, S. (2010). Muscularity and attractiveness as predictors of human egalitarianism. Personality and Individual Differences, 50, 636- 640

Riley, D. (1987). Time and crime: the link between teenager lifestyle and delinquency. Journal of Quantitative Criminology, 3, 339-354.

Sell, A., Tooby, J., \& Cosmides, L. (2009). Formidability and the logic of human anger. PNAS Proceedings of the National Academy of Sciences of the United States of America, 106, 15073-15078.

Sosis, R., \& Alcorta, C. (2003). Signaling, solidarity, and the sacred: the evolution of religious behavior. Evolutionary Anthropology, 12, 265-274.

Tetlock, P. E., Kristel, O., Elson, B., Green, M., \& Lerner, J. (2000). The psychology of the unthinkable: taboo trade-offs, forbidden base rates, and heretical counterfactuals. Journal of Personality and Social Psychology, 78, 853-870.

Tooby, J., \& Cosmides, L. (2000). Cognitive adaptations for kin-based coalitions: human kinship systems at the intersection between collective action and kin selection. Comment on Group Nepotism and Human Kinship by Doug Jones. Current Anthropology, 41, 803-804.

Tooby, J., \& Cosmides, L. (2010). Groups in mind: the coalitional roots of war. In Høgh-Olesen, H. (Ed.) Human Morality \& Sociality: Evolutionary \& Comparative Perspectives (pp. 191-234). London: Palgrave Macmillam.

Tooby, J., Cosmides, L., \& Price, M. E. (2006). Cognitive adaptations for n-person exchange: the evolutionary roots of organizational behavior. Managerial and Decision Economics, 27, 103-129.

Turiel, E. (1983). The development of social knowledge. Cambridge: Cambridge University Press.

von Rueden, C., Gurven, M., \& Kaplan, H. (2008). The multiple dimensions of male social status in an Amazonian society. Evolution and Human Behavior, 29, 402-415.

Weeden, J., Cohen, A. B., \& Kenrick, D. T. (2008). Religious attendance as reproductive support. Evolution \& Human Behavior, 29, 327-334

Wilson, D. S. (2002). Darwin's cathedral: evolution, religion and the nature of society. Chicago: University of Chicago Press.

Zhang, L., \& Zhang, S. (2004). Reintegrative shaming and predatory delinquency. Journal of Research in Crime and Delinquency, 41, 433-453. 
Table 1. Effects of social support and control variables on moralization

\begin{tabular}{lc}
\hline & Model \\
\hline Social support: friends & $-0.08^{* * *}$ \\
Social support: religious individuals & $0.11^{* * *}$ \\
Social support: family & $0.08^{* * *}$ \\
Importance of friendship & $-0.03^{* * *}$ \\
Importance of religion & $0.23^{* * *}$ \\
Importance of family & $0.08^{* * *}$ \\
Sex (female) & $0.02 * * *$ \\
Age & $0.22^{* * *}$ \\
No. of children & $0.02 *$ \\
Education & $-0.09 * * *$ \\
Income & $-0.03 * * *$ \\
\hline $\mathrm{R}^{2}$ & 0.25 \\
\hline
\end{tabular}

Notes. $\mathrm{N}=21,131$. Coefficients are standardized regression coefficients from OLS regression. $* \mathrm{p}<.05, * * \mathrm{p}<.01, * * * \mathrm{p}<.001$. 
Table 2. Factor analysis of moralization in distinct domains

\begin{tabular}{|c|c|c|}
\hline & $\begin{array}{l}\text { Moralization in } \\
\text { cooperation domain }\end{array}$ & $\begin{array}{l}\text { Moralization in } \\
\text { mating domain }\end{array}$ \\
\hline Someone accepting a bribe & 0.64 & -0.07 \\
\hline Cheating on taxes & 0.62 & -0.04 \\
\hline Driving under the influence of alcohol & 0.62 & -0.07 \\
\hline Lying & 0.57 & 0.11 \\
\hline Littering & 0.57 & -0.04 \\
\hline Speeding & 0.56 & 0.05 \\
\hline Joyriding & 0.53 & -0.06 \\
\hline Claiming government benefits & 0.53 & -0.08 \\
\hline Paying cash & 0.51 & 0.13 \\
\hline Adultery & 0.42 & 0.28 \\
\hline Smoking in public buildings & 0.38 & 0.21 \\
\hline Taking soft drugs & 0.37 & 0.28 \\
\hline Divorce & -0.04 & 0.80 \\
\hline Abortion & -0.03 & 0.77 \\
\hline Homosexuality & -0.03 & 0.68 \\
\hline Euthanasia & 0.04 & 0.57 \\
\hline Suicide & 0.15 & 0.50 \\
\hline Having casual sex & $0.32-$ & 0.46 \\
\hline Eigen value & 5.08 & 1.54 \\
\hline
\end{tabular}

Notes. $\mathrm{N}=31,786$. Entries are loadings from a principal factor analyses with oblique rotation. Bold numbers show the primary factor on which an item loads. 
Table 3. Effects of social support and control variables on moralization in the domains of mating and cooperation

\begin{tabular}{lcc}
\hline & $\begin{array}{c}\text { Mating } \\
\text { domain }\end{array}$ & $\begin{array}{c}\text { Cooperation } \\
\text { domain }\end{array}$ \\
\hline Social support: friends & $-0.09^{* * *}$ & $-0.05^{* * *}$ \\
Social support: religious individuals & $0.16^{* * *}$ & $0.04 * * *$ \\
Social support: family & $0.10^{* * *}$ & $0.05 * * *$ \\
Importance of friendship & $-0.06^{* * *}$ & 0.00 \\
Importance of religion & $0.28^{* * *}$ & $0.12 * * *$ \\
Importance of family & $0.04 * * *$ & $0.11 * * *$ \\
Sex (female) & $-0.03^{* * *}$ & $0.08^{* * *}$ \\
Age & $0.14 * * *$ & $0.23 * * *$ \\
No. of children & $0.03^{* * *}$ & 0.01 \\
Education & $-0.13^{* * *}$ & $-0.03 * * *$ \\
Income & $-0.03^{* * *}$ & $-0.02 *$ \\
\hline $\mathrm{R}^{2}$ & 0.28 & 0.14 \\
\hline
\end{tabular}

Notes. $\mathrm{N}=21,131$. Coefficients are standardized regression coefficients from OLS regression. * $\mathrm{p}<.05, * * \mathrm{p}<.01, * * * \mathrm{p}<.001$. 
Table 4. Interactions between social support from friends and investment strategies on moralization in the domains of mating and cooperation

\begin{tabular}{lcc}
\hline & $\begin{array}{c}\text { Mating } \\
\text { domain }\end{array}$ & $\begin{array}{c}\text { Cooperation } \\
\text { domain }\end{array}$ \\
\hline Social support: friends & $-0.13^{* * *}$ & $-0.17 * * *$ \\
Investment strategy & $0.18^{* * *}$ & $0.08^{* * *}$ \\
Social support: friends $\times$ investment strategy & $0.06^{*}$ & $0.14 * * *$ \\
Social support: religious individuals & $0.16^{* * *}$ & $0.03 * * *$ \\
Social support: family & $0.08^{* * *}$ & $0.05^{* * *}$ \\
Importance of friendship & $-0.05^{* * *}$ & -0.01 \\
Importance of religion & $0.25^{* * *}$ & $0.10^{* * *}$ \\
Importance of family & $0.03 * * *$ & $0.09 * * *$ \\
Sex (female) & $-0.02 * *$ & $0.08^{* * *}$ \\
Age & $0.13 * * *$ & $0.22 * * *$ \\
No. of children & 0.01 & 0.01 \\
Education & $-0.10^{* * * *}$ & $-0.04 * * *$ \\
Income & $-0.02^{* *}$ & $-0.02^{*}$ \\
\hline $\mathrm{R} 2$ & 0.32 & 0.16 \\
\hline
\end{tabular}

Notes. $\mathrm{N}=16,946 / 20,623$. Coefficients are standardized regression coefficients from OLS regression. $* \mathrm{p}<.05, * * \mathrm{p}<.01, * * * \mathrm{p}<.001$. 
Figure 1. Predicted levels of moralization in the mating and cooperation domains conditioned by investment strategy and social support from friends

A. Mating domain

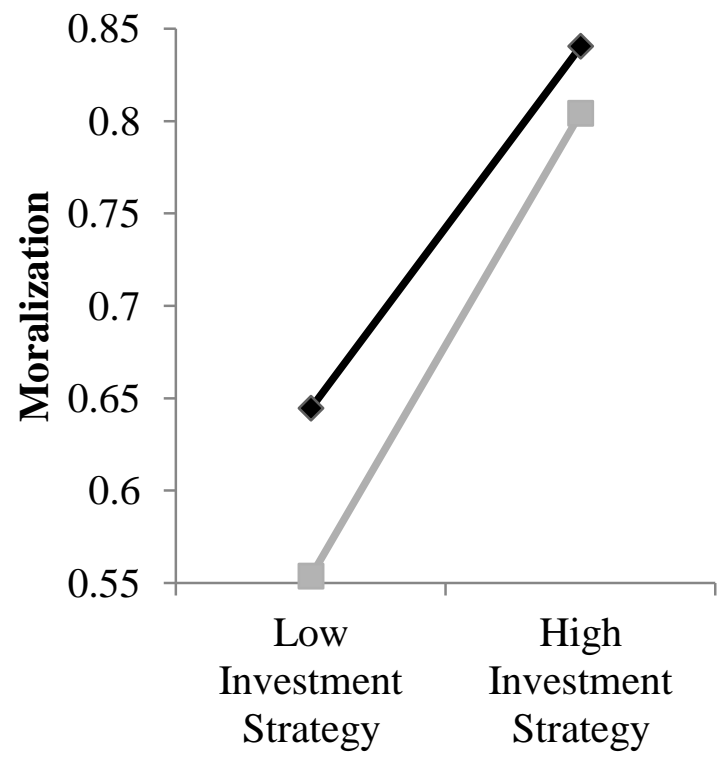

B. Cooperation domain

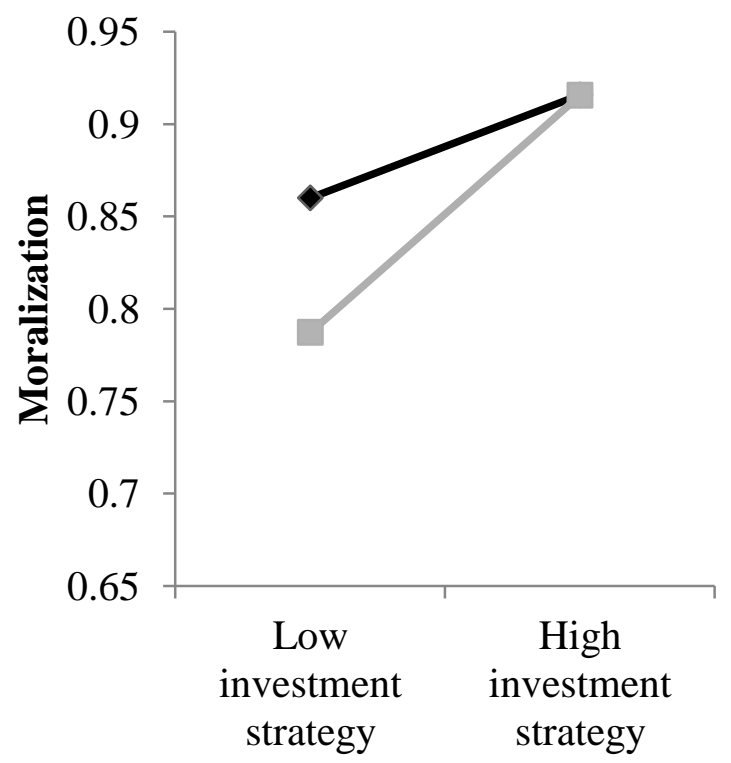

- - Low social support from friends

- - High social support from friends

Notes: predicted levels of moralization have been calculated using unstandardized regression coefficients from OLS regression presented in Table 4. Moralization was measured on a scale from 0 (low) to 1 (high). Predicted values are shown for minimum and maximum levels of support and investment strategies. Control variables have been set to their midpoint and, in the case of sex, females. 
Online Supplemental Materials for:

\section{Moralization as protection against exploitation: do individuals without allies moralize more?}

\section{Contents:}

1. Additional Study: Moralization across Domains (EVS 1981)

2. Table A1. Effects of Friends rather than Family as Source of Support on Moralization across Domains

3. Table A2. Interactions between Family and Religious Support and Investment Strategies on Moralization in the Domains of Mating and Cooperation

\section{Additional Study: Moralization across Domains (EVS 1981)}

As argued in the main text, it is plausible that people with many friends will have more to gain by engaging in promiscuity and that this constitutes an independent psychological pressures for downregulating moralization of certain behaviors. If this dynamic fully explains the results in the main text, we should not be able to find effects of friendships on moralization outside of the sexual domain. The analyses presented in the main text showed small but significant effects of social support of friends on moralization outside the domain of reproduction. Here, we try to replicate that finding using other data. Luckily, the 1981 EVS includes a large number of questions about moralization of all kinds of behavior outside the sexual domain as well as measures about allies in the form of friends, although the latter measure is not as optimal as those analyzed in the main text. 


\section{Materials and Methods}

From the data available in the 1981 EVS, we created three different scales to moralization in order to investigate the breadth of the effects of social support. First, a scale of moralization of behavior in the sexual domain was created on the basis of the perceived justifiability of the following: homosexuality, prostitution, abortion, divorce, taking soft drugs, adultery, and sex under the legal age of consent $(\alpha=.84)$. Second, an additive scale of moralization of behavior within the domain of cooperation was created that focused specifically on behavior that harms public goods. The scale was based on answers about the justifiability of the following behaviors: claiming government benefits that one is not entitled to, avoiding a fare on public transport, cheating on taxes and someone accepting a bribe $(\alpha=.69)$. Finally, an additive scale of moralization of behavior within the domain of cooperation focusing on privately harmful behavior was created. The scale was based on answers about the justifiability of the behaviors relating to property violations and aggression: joyriding, lying, political assassination, to buy stolen goods, keeping money that you have found, fighting with the police, failing to report damage you've done accidentally to a parked vehicle and killing in self-defense $(\alpha=.73)$.

The theoretically important independent variable is the amount of friends that the self can call upon as coalitional back-up in a conflict. In the main text, this has been operationalized as how much time the respondent spends with friends. These measures were not available in the 1981 EVS. Yet, while we cannot gauge how much support individuals are able to draw from friends, we can obtain a measure of the source from which the individual primarily draw social support. Hence, the 1981 EVS included a question about how the respondent preferred to spend leisure time. Two of the options, which also happened to be the ones most frequently chosen by respondents, related to dominant sources of social support: with friends and with family (the other options were to spend time alone, in a lively place or to send the time on all options equally). Decisions about how to 
spend your time are investment decisions and, hence, reflect expectations about returns. In this way, the decision to spend time with friends rather than family or vice verse reveals an expectation that one is able to draw on support from this particular source in the future. Our key independent variable, then, is a comparison of individuals who prefer spending time with friends with individuals who prefer to spend time with family. A high value on this dichotomous variable reflects a preference for friends.

Importantly, while this variable is not optimal from the perspective of the here presented theory (which is an argument about the psychological effects of individual differences in amount of social support from, in particular, friends), it does provide us with a possibility of testing the viability of the alternative explanation, as argued below.

In total, 11,287 individuals from 15 Western countries have provided valid answers to our main variables (Belgium, Canada, Denmark, France, Iceland, Ireland, Italy, Netherlands, Norway Spain, Sweden, Great Britain, United States, Germany West and Northern Ireland). Furthermore, in the data it is possible to control for some important variables: sex, age, whether the respondent is married and whether the respondent is employed.

\section{Results}

How leisure time is spent reflects, in part, mating strategies and it is possible that this could explain the effect on moralization of promiscuous sexual practices. In such a perspective, the choice between friends and family would reflect a short- and long-term mating strategy, respectively. If this choice only reflects mating strategies, this choice should first and foremost influence moralization of practices within the sexual domain but not outside. Yet, if having coalitional allies in the form of friends do not just reflect mating strategies but also influence self-assessments of one's formidability, friendships should additionally influence an individual's general tendency to 
moralize across multiple domains. In other words, individuals with many friends should not just be less moralistic when it comes to sexual practices but also when it comes to other types of behaviors.

Table A1 displays the effect of the choice between family and friends and moralization of behavior in the three domains. As can be seen, the effect is not limited to moralization of sexual behavior (Model 1) but extends, with equal strength, to the measure of moralization of privately harmful behaviors in the cooperation domain (Model 2) as well as behaviors of publicly harmful behaviors in the same domain (Model 3). This is inconsistent with the argument that investing in friends only reflects mating strategies but consistent with the argument that having friends also up-regulates formidability such that moralization as a general strategy becomes less attractive across domains. 
Table A1. Effects of Friends rather than Family as Source of Support on Moralization Across Domains.

\begin{tabular}{lccc}
\hline & $\begin{array}{c}\text { Moralization in } \\
\text { Mating Domain }\end{array}$ & $\begin{array}{c}\text { Moralization in } \\
\text { Cooperation Domain } \\
\text { (Private Harms) }\end{array}$ & $\begin{array}{c}\text { Moralization in } \\
\text { Cooperation Domain } \\
\text { (Public Harms) }\end{array}$ \\
Model \# & 1 & 2 & 3 \\
\hline Support from family & $-.09^{* * *}$ & $-.11^{* * *}$ & $-.11^{* * *}$ \\
or friends (friends) & $.12^{* * *}$ & $.06 * * *$ & $.08^{* * *}$ \\
Sex (female) & $.26^{* * *}$ & $.27 * * *$ & $.19 * * *$ \\
Age & $.06^{* * *}$ & $.03 * * *$ & $.03 * *$ \\
Married (yes) & $.02 *$ & $.02 * *$ & $.02 *$ \\
Employed (yes) & .13 & .14 & .09 \\
\hline $\mathrm{R}^{2}$ & & 09 & \\
\hline
\end{tabular}

Notes. $\mathrm{N}=11,129$. Coefficients are standardized regression coefficients from OLS regression. Data is from EVS 1981. * $\mathrm{p}<.05, * * \mathrm{p}<.01, * * * \mathrm{p}<.001$ 
Table A2. Interactions between Family and Religious Support and Investment Strategies on Moralization in the Domains of Mating and Cooperation.

\begin{tabular}{lcc}
\hline & $\begin{array}{c}\text { Mating } \\
\text { Domain }\end{array}$ & $\begin{array}{c}\text { Cooperation } \\
\text { Domain }\end{array}$ \\
\hline Social Support: Friends & $-.08^{* * *}$ & $-.06^{* * *}$ \\
Investment Strategy & $.28^{* * *}$ & $.14^{* * *}$ \\
Social Support: Religious Individuals & $.33^{* * *}$ & .02 \\
Social Support: Religious $\times$ Investment Strategy & $-.19^{* * *}$ & .02 \\
Social Support: Family & $.15^{* * *}$ & .00 \\
Social Support: Family $\times$ Investment Strategy & $-.08^{* *}$ & .05 \\
Importance of Friendship & $-.05^{* * *}$ & -.01 \\
Importance of Religion & $.25^{* * *}$ & $.10^{* * *}$ \\
Importance of Family & $.03^{* * *}$ & $.10^{* * *}$ \\
Sex (female) & $-.02^{* *}$ & $.08^{* * *}$ \\
Age & $.13^{* * *}$ & $.22^{* * *}$ \\
No. of Children & .01 & .01 \\
Education & $-.10^{* * *}$ & $-.03^{* * *}$ \\
Income & $-.02^{* *}$ & $-.02^{*}$ \\
\hline $\mathrm{R}^{2}$ & .32 & .16 \\
\hline Notes. N & \\
\hline
\end{tabular}

Notes. $\mathrm{N}=16,946 / 20,623$. Coefficients are standardized regression coefficients from OLS regression. $* \mathrm{p}<.05, * * \mathrm{p}<.01, * * * \mathrm{p}<.001$ 